\title{
Effect of Recombinant Soluble CD4 on Human Peripheral Blood Lymphocyte Responses In Vitro
}

\author{
Margaret A. Liu* and Theresa Liu ${ }^{\ddagger}$ \\ ${ }^{*}$ Endocrine Unit and Medical Services, Massachusetts General Hospital and Harvard Medical School, Boston, Massachussets 02114; \\ and Center for Cancer Research, Massachusetts Institute of Technology, Cambridge, Massachusetts 02139; and ${ }^{\ddagger}$ Department of Cell \\ Biology \& Immunology, Biogen Research Corporation, Cambridge, Massachusetts 02142
}

\begin{abstract}
We have previously demonstrated that recombinant soluble CD4 protein (rsT4) blocks both HIV-1 infection of CD4 bearing lymphocytes and syncytium formation in vitro. (Recombinant soluble CD4 is designated by rsT4.) Hence, we suggested the use of rsT4 in therapy for AIDS or the prevention of HIV-1 infection in individuals with a known risk of exposure. However, concerns arose that rsT4 might be immunosuppressive because of its implicated role in the enhancement of certain lymphocyte activation events through its engagement of $\mathrm{MHC}$ class II molecules on target cells. We therefore assessed the effect of recombinant soluble CD4 upon a number of functional and activation parameters of lymphocytes, including cellular proliferation, IL-2 secretion, and cytolytic capability, after antigenic or mitogenic stimulation. We report here that rsT4, at 60-fold over the concentration needed to block acute HIV-1 infection in vitro, does not significantly inhibit the activation of human peripheral blood lymphocytes by either PHA, tetanus toxoid or allogeneic cells. These results indicate that rsT4 will potentially exert minimal immunosuppressive effects in vivo, thus supporting the feasibility of clinical trials of rsT4 in the treatment or prevention of AIDS. In addition, the implications of these results for the interactions between CD4 and MHC class II molecules during lymphocyte activation are discussed.
\end{abstract}

\section{Introduction}

Human immunodeficiency virus type 1 (HIV-1), the etiologic agent of acquired immunodeficiency syndrome (AIDS), infects cells by binding to a cell surface molecule, the CD4 antigen, present on certain cells of the immune system (1-5). In particular, the CD4 antigen has served as a phenotypic marker for those $\mathrm{T}$ lymphocytes that recognize antigen on cells bearing MHC class II molecules (6-10). Functionally, most of the $\mathrm{CD}^{+}$lymphocytes in human peripheral blood are helper/inducer cells, although $\mathrm{CD}^{+}$cytotoxic cells have been detected (11). The cell surface CD4 molecule has been thought to en-

Address reprint requests to Dr. T. Liu, Biogen Research Corporation, Cambridge, MA 02142. 1988.

Received for publication 1 July 1988 and in revised form 31 August

J. Clin. Invest.

(C) The American Society for Clinical Investigation, Inc.

$0021-9738 / 88 / 12 / 2176 / 05 \$ 2.00$

Volume 82, December 1988, 2176-2180 hance the interactions between the $\mathrm{T}$ lymphocyte and the antigen presenting cell by binding to monomorphic determinants on the MHC class II molecule (12-17).

Recombinant soluble CD4 protein (lacking its transmembrane and cytoplasmic domains) has recently been expressed and shown to be capable of inhibiting virus infection and HIV-1-induced syncytium formation in vitro (18-22). These findings have led to proposals for the use of recombinant soluble CD4 (rsT4) ${ }^{1}$ as an antiviral therapy for HIV-1 infection. Concerns exist however, that rsT4 could act as an immunosuppressant by competing with cell surface CD4 for binding to its putative ligand, MHC class II molecules, and as a result compromise activation of $\mathrm{CD}^{+}$lymphocytes. Partial inhibition of lymphokine production and cytotoxic activity by antiCD4 and anti-class II antibodies in several systems supports such concerns $(12,13,17,23)$.

To determine if rsT4 has immunosuppressive properties, we examined the peripheral blood lymphocyte responses to three types of antigenic and mitogenic stimuli in vitro in the presence and absence of rsT4 or control antibodies. We utilized freshly isolated human PBL as the responder cells in order to simulate the physiologic milieu and responses. The three types of stimuli were allogeneic cells, soluble antigen, and mitogenic lectin. The responses of the peripheral blood lymphocytes that were examined included proliferation, cell surface phenotype, IL-2 production, and cytolytic capability.

\section{Methods}

Peripheral blood lymphocytes and cell lines

Fresh PBL were obtained from six healthy donors by isolating heparinized venous blood on Ficoll-Paque. All of the donors had normal CD4+/CD8 + $T$ cell ratios, and none were in any high risk category for HIV-1 infection. The lymphocytes were washed twice in RPMI and resuspended at $2 \times 10^{6} \mathrm{cells} / \mathrm{ml}$ and $1 \times 10^{6}$ cells $/ \mathrm{ml}$ in $\mathrm{K}$ medium (RPMI 1640 supplemented with $10 \%$ FCS, $50 \mu \mathrm{M}$ 2-mercaptoethanol, $100 \mathrm{U} / \mathrm{ml}$ penicillin, $100 \mu \mathrm{g} / \mathrm{ml}$ streptomycin, $2 \mathrm{mM} \mathrm{L}$-glutamine, and $10 \mathrm{mM}$ Hepes). The lymphoblastoid B cell line JY, was maintained in $\mathrm{K}$ media. Before use, the JY cells were washed and resuspended at 2 $\times 10^{6} \mathrm{cell} / \mathrm{ml}$ in $\mathrm{K}$ medium then irradiated with $6,000 \mathrm{rad}$.

\section{rsT4 and antibodies}

rsT4 was purified from conditioned medium of $\mathrm{CHO}$ cells expressing BG 381. The purified protein was generously provided by W. Meier and J. Maraganore, Biogen. Antibodies directed against CD4 were included as controls: OKT4a, an anti-CD4 antibody known to inhibit

1. Abbreviations used in this paper: $\mathrm{rsT} 4$, designation for recombinant soluble CD4. 
Table I. Effect of Anti-CD4 Antibodies, Control Ab, and Recombinant Soluble CD4 upon Mixed Lymphocyte Proliferation

\begin{tabular}{llccccc}
\hline & \multicolumn{1}{c}{ Donor 1 } & \multicolumn{1}{c}{ Donor 2 } & \multicolumn{1}{c}{ Donor 3} & Donor 4 & Donor 5 & Donor 6 \\
\hline Control & $41,056 \pm 890$ & $18,035 \pm 339$ & $27,460 \pm 1,303$ & $26,914 \pm 2,494$ & $22,300 \pm 2,363$ & $30,666 \pm 1,164$ \\
81AB7 & $34,019 \pm 787$ & $15,547 \pm 775$ & $25,481 \pm 1,802$ & $21,514 \pm 452$ & $25,348 \pm 1,617$ & $29,739 \pm 1,845$ \\
OKT4a & $16,205 \pm 919$ & $8,668 \pm 515$ & $12,752 \pm 403$ & $8,476 \pm 301$ & $14,215 \pm 648$ & $16,623 \pm 973$ \\
OKT4 & $19,997 \pm 1,279$ & $13,360 \pm 801$ & $14,663 \pm 450$ & $11,221 \pm 1,976$ & $15,295 \pm 392$ & $20,332 \pm 883$ \\
rsT4 & $31,547 \pm 1,463$ & $14,662 \pm 253$ & $23,258 \pm 1,330$ & $20,865 \pm 879$ & $23,845 \pm 2,853$ & $29,512 \pm 1,363$ \\
\hline
\end{tabular}

The proliferation of PBL derived from six normal donors versus JY B lymphoblastoid cells was assessed by $\left[{ }^{3} \mathrm{H}\right]$ thymidine incorporation on day 3 of the MLR. The effect of control antibody $81 \mathrm{AB} 7(5 \mu \mathrm{g} / \mathrm{ml}), 2$ anti-CD4 antibodies (OKT4a, OKT4, both $5 \mu \mathrm{g} / \mathrm{ml}$ ), and recombinant soluble CD4 (rsT4, $30 \mu \mathrm{g} / \mathrm{ml}$ ) added to the MLR at the time of initiation is shown. The numbers are average counts per minute of triplicate assays \pm 1 SD. Recombinant soluble CD4 (rsT4) has a minimal inhibitory effect at $30 \mu \mathrm{g} / \mathrm{ml}$, whereas OKT4a and OKT4 have marked inhibitory effects at $5 \mu \mathrm{g} / \mathrm{ml}$.

a variety of $T$ cell responses $(11,23-25)$, was purchased from Orthomune; OKT4 was purified conventionally from the conditioned medium of OKT4 hybridoma cells purchased from American Type Culture Collection. 81AB7, a gift from D. Hess (Biogen Research Corp.) was selected to control for any effect due to the IgG2a Fc region of OKT4a. It is specific for bee venom phospholipase A2 with no known cross-reactivity with human phospholipase.

\section{Stimulation of peripheral blood lymphocytes}

Mixed lymphocyte responses (MLR). In 96 well Costar microtiter plates, wells containing $1 \times 10^{5} \mathrm{PBL}$ and $1 \times 10^{5} \mathrm{JY}$ in $200 \mu \mathrm{l}$ of $\mathrm{K}$ medium were set up in triplicate. Samples for baseline proliferation contained no JY; control MLRs contained PBL and JY. Other samples contained, in addition to the PBL and JY, OKT4a (IgG2a, $5 \mu \mathrm{g} / \mathrm{ml})$, OKT4 (IgG2b, $5 \mu \mathrm{g} / \mathrm{ml}$ ), rsT4 ( $30 \mu \mathrm{g} / \mathrm{ml}$ ), or 81 AB7 (IgG2a, $5 \mu \mathrm{g} / \mathrm{ml}$ ).

Specific soluble antigenic stimulation. Samples in triplicate contained $2 \times 10^{5} \mathrm{PBL}, 50 \mu \mathrm{g} / \mathrm{ml}$ tetanus toxoid with or without $81 \mathrm{AB} 7$, OKT4a, OKT4, or rsT4 (at the concentrations given above) in $200 \mu \mathrm{l}$ of K medium. Donors 1-3 had been boosted with tetanus toxoid 7-8 d before blood donation as none of them had received the toxoid within $10 \mathrm{y}$. Data derived from donor 4 was excluded since he had never received a complete primary immunization series, resulting in extremely low proliferation $(1,500 \mathrm{cpm})$.

Mitogenic activation. PBL were cultured in triplicate samples in $200 \mu \mathrm{l}$ of K medium with $5 \mu \mathrm{g} / \mathrm{ml}$ of PHA (Difco Laboratories, Detroit, $\mathrm{MI})$ in the presence and absence of $81 \mathrm{AB} 7, \mathrm{OKT} 4 \mathrm{a}, \mathrm{OKT} 4$, or rsT4 at the concentrations specified above.

Dose-response effect. Mixed lymphocyte responses were generated between $1 \times 10^{5} \mathrm{PBL}$ and $1 \times 10^{5} \mathrm{JY}$ cells per well in the presence and absence of $81 \mathrm{AB} 7$, OKT4a, OKT4, and rsT4 at the concentrations noted above as well as the following dilutions: 1:10, 1:102 $1: 10^{4}, 1: 10^{6}$, and $1: 10^{8}$ in triplicate in a final volume of $200 \mu \mathrm{l}$ of $\mathrm{K}$ medium.

\section{Quantitation of $I L-2$ production}

$50 \mu$ l of supernatant was harvested from cultures of PBL from donors 1,2 , and 6 that had been exposed to tetanus toxoid in the presence and absence of rsT4 and the control antibodies. IL-2 production was measured by standard CTLL proliferation assays (15).

\section{$P B L$ proliferation assays}

At the time specified below, $100 \mu \mathrm{l}$ of $\mathrm{K}$ medium containing $1 \mu \mathrm{Ci}$ of $\left[{ }^{3} \mathrm{H}\right]$ thymidine was added to each well. Cells were harvested $17 \mathrm{~h}$ later with a Skatron harvester and filter disks placed in $1 \mathrm{ml}$ of beta-fluor and counted in a Beckman gamma counter. The counts per minute for each sample is calculated as the mean of the triplicate values. The data for the day 3 MLR proliferation \pm 1 SD are shown in Table I. In all the figures, the mean triplicate values for each donor were calculated as a percentage of the control using the equation $(\mathrm{E}-\mathrm{S}) /(\mathrm{C}-\mathrm{S})$, where $\mathrm{E}$ is the experimental $\left[{ }^{3} \mathrm{H}\right]$ thymidine incorporation $(\mathrm{cpm})$ in the presence of the antibody or protein, $\mathrm{S}$ the $\left[{ }^{3} \mathrm{H}\right]$ thymidine incorporation $(\mathrm{cpm})$ of PBL alone, and " $\mathrm{C}$ " the $\left[{ }^{3} \mathrm{H}\right]$ thymidine incorporation of the control PBL plus stimulus (no antibody or rsT4 present). These percent control values for the six donors were then averaged to yield the mean values. Proliferation assays were done at 72,96 , and $120 \mathrm{~h}$ for the MLRs, at $96 \mathrm{~h}$ for the MLR with dilutions of rsT4 and antibodies, at 96 $\mathrm{h}$ for the tetanus toxoid stimulation, and at 48 and $72 \mathrm{~h}$ for the PHA activation, since these are the optimal response times for the various stimuli.

\section{Phenotype analysis}

Phenotype of the responder cells were analyzed by flow cytometry on day zero (before initiation of the MLR), and again at day 4 or day 5 using two-color analysis with fluorescein-labeled anti-CD4 (FITC-

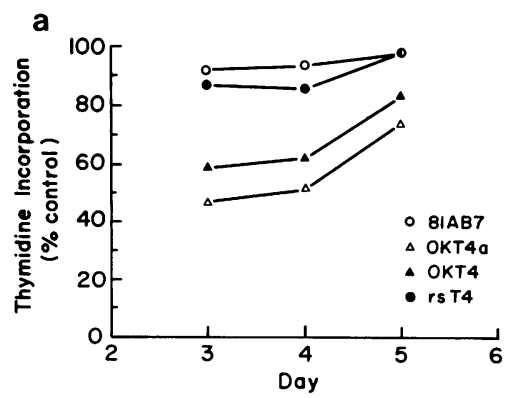

Figure 1. (a) MLR between peripheral blood lymphocytes from six normal donors and JY cells were established in the absence and presence of control antibody (81AB7), anti CD4 antibodies (OKT4a, OKT4) and recombinant soluble CD4 (rsT4) (see Table I legend). The average triplicate value was expressed as a percentage of the control for each donor and these percent control values for the six donors were then averaged to yield the mean values which are plotted here for days

3-5. rsT4 at concentration of $30 \mu \mathrm{g} / \mathrm{ml}$ has a minimal inhibitory effect upon proliferation for days 3 and 4 , whereas the effect of OKT4a and OKT4 at $5 \mu \mathrm{g} / \mathrm{ml}$ is more marked for all $3 \mathrm{~d}$. (b) The MLR were established as before. The same initial concentrations of antibodies $81 \mathrm{AB} 7, \mathrm{OKT} 4 \mathrm{a}, \mathrm{OKT} 4(5 \mu \mathrm{g} / \mathrm{ml})$, and rsT4 $(30 \mu \mathrm{g} / \mathrm{ml})$ were used as well as 10-fold dilutions of each. On day 4 the proliferation was assessed by thymidine incorporation and the values expressed as percents of the control proliferation as described in $a$. The minimal inhibitory effect of rsT4 is seen only at the highest $30 \mu \mathrm{g} / \mathrm{ml}$ concentration, whereas the greater inhibitory effects of OKT4a and OKT4 persist to $50 \mathrm{ng} / \mathrm{ml}$. 


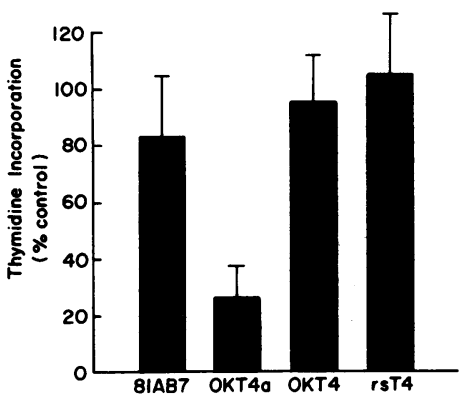

$\mu \mathrm{g} / \mathrm{ml})$ or $\mathrm{rsT} 4(30 \mu \mathrm{g} / \mathrm{ml})$. Proliferation was assayed on day 4 by $\left[{ }^{3} \mathrm{H}\right]$ thymidine incorporation and the results of the cultures containing antibody or rsT4 were expressed as a percentage of the control for each individual, which were then averaged to yield the mean percent control for each experimental condition. rsT4 had no net effect whereas OKT4a had a marked inhibitory effect upon proliferation.

Leu3a) and phycoerythrin-labeled anti-CD8 (PE-Leu2a). On day 0 and day 4 for donors $1-3$, and day 5 for donors $4-6,1 \times 10^{5}$ cells from each MLR were placed in duplicate test tubes, centrifuged, then resuspended in $50 \mu \mathrm{l}$ of medium containing PBS $(0.14 \mathrm{M} \mathrm{NaCl}, 1 \mathrm{mM} \mathrm{KCl}$, and $3.7 \mathrm{mM}$ sodium-potassium phosphate), 5\% FCS and $0.02 \%$ sodium azide. $30 \mu \mathrm{l}$ of control antibody or FITC-Leu3a/PE-Leu2a (Simultest Immune Monitoring Kit; Becton Dickinson, Mountain View, CA) was added. After 30 min incubation on ice in the dark, the cells were fixed with $3 \%$ formaldehyde before analysis on a Becton Dickinson FACS Star flow cytometer.

\section{Cytolytic assays}

Standard 4-h ${ }^{51} \mathrm{Cr}$ killing assays were performed using MLR responder cells from two donors at an E:T ratio of 10:1 in the presence and absence of rsT4 or the antibodies at their usual concentrations.

\section{Results}

Table I and Fig. $1 a$ show the extent of PBL proliferation in an MLR in the presence of $30 \mu \mathrm{g} / \mathrm{ml}$ of rsT4. This rsT4 concentration far exceeds the $0.5 \mu \mathrm{g} / \mathrm{ml}$ level needed to inhibit HIV-1 replication in acutely infected $\mathrm{H} 9$ cells as measured by p24 antigen production (Johnson, V. A., personal communication). In contrast, $5 \mu \mathrm{g} / \mathrm{ml}$ of OKT $4 \mathrm{a}$ or OKT 4 caused marked inhibition of $\sim 50 \%$ on day 3 . The mean values of triplicate samples (with their standard deviations) for day 3 of the MLR are given in Table I to illustrate the magnitude of the response for the individual donors; the relative effect of each antibody or rsT4 among the individuals was reasonably consistent. These values were then expressed as a percentage of the control MLR for each individual, averaged to yield the mean from the six donors and are shown in Fig. $1 a$ for days 3, 4, and 5. The dose-response curves in Fig. $1 b$ show that the inhibitory effect of the two anti-CD4 antibodies diminished with decreasing concentration. A slight inhibitory effect of rsT4 was discernible at $30 \mu \mathrm{g} / \mathrm{ml}$. Extension of the dose range of rsT4 to 200 $\mu \mathrm{g} / \mathrm{ml}$ using PBLs from two other healthy donors did not result in inhibition of MLR proliferation. The level of rsT4 as detected by a sandwich ELISA using both OKT4 and OKT4a monoclonal antibodies, and the functional activity as measured by binding to recombinant HIV-1 envelope glycoprotein, gp 120, remained the same before and after 3 and $4 \mathrm{~d}$ in tissue culture in a MLR indicating that extensive proteolysis or sequestration did not occur.

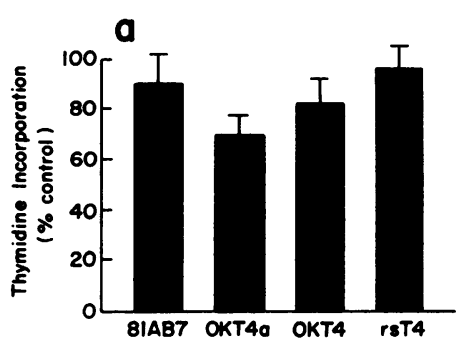

b

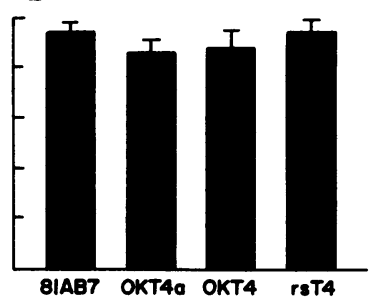

Figure 3. The effect of $81 \mathrm{AB} 7$, OKT4a, OKT4, and rsT4 upon mitogen-induced proliferation of peripheral blood lymphocytes from six normal donors. Peripheral blood lymphocytes were stimulated with 5 $\mu \mathrm{g} / \mathrm{ml}$ of phytohemagglutinin in the presence and absence of antibodies $(5 \mu \mathrm{g} / \mathrm{ml})$ or rsT4 $(30 \mu \mathrm{g} / \mathrm{ml})$. Proliferation was assayed at 48 $\mathrm{h}(a)$ and $72 \mathrm{~h}(b)$ and the results were calculated as in Fig. 2. rsT4 caused no significant inhibition, and OKT4a and OKT4 were moderately antiproliferative early on.

In addition, rsT4 did not affect the phenotype distribution or the cytolytic activity of cells in the MLR cultures. Analysis of the MLR responder cells by fluorescent flow cytometry demonstrated that the presence of rsT4, OKT4, or $81 \mathrm{AB} 7$ during generation of the MLR did not consistently alter the CD4/CD8 ratios of the cells from that of the control MLR (data not shown). In the presence of OKT $4 a,<0.02 \%$ of the cells were $\mathrm{CD}^{+}$. (This appears to be partially caused by blocking of FITC-Leu3a staining by persistent OKT4a in the culture medium.) Standard ${ }^{51} \mathrm{Cr}$ release cytolytic assays of responder cells derived from the control MLR showed that the presence of rsT4 or the antibodies did not alter the lytic ability of the cells which averaged $34 \%$ specific lysis of JY at an effector to target cell ratio of 10:1.

The proliferative response of PBL to tetanus toxoid (50 $\mu \mathrm{g} / \mathrm{ml}$ ) was on average unaffected by rsT4 (Fig. 2), even though this stimulation is MHC class II restricted and selectively activates $\mathrm{T}$ cells which are $\mathrm{CD}^{+}(26-28)$. The range for the individual donors varied from 82 to $130 \%$ of the respective controls, the mean being $105 \%$. OKT4a was highly inhibitory but OKT4 had no significant effect. In addition, when IL-2 production by cells from donors 1,2 , and 6 was examined, the cultures stimulated in the presence of rsT4 varied from 81 to $140 \%$ of control on the day of optimal production, while OKT4a containing cultures were all completely inhibited. The variation as well as the extent of proliferation of the control cultures were not related to whether the individual had been boosted with tetanus toxoid the week before blood donation.

rsT4 had no effect on the generalized mitogenic effect of PHA for mature human T cells. As previously demonstrated (29), both OKT4a and OKT4 were less effective in inhibiting this PBL response than the MLR-induced proliferation. The maximal antibody effect was seen on day 2 , with a smaller effect on day 3 after the one-time addition of PHA $(5 \mu \mathrm{g} / \mathrm{ml})$ on day zero (Fig. 3).

\section{Discussion}

Our experiments show that rsT4 does not significantly inhibit human PBL responses to allogeneic cell, tetanus toxoid stimulation, or PHA in vitro. The use of PBL rather than T cell clones (19) allowed us to assess responses to primary as well as secondary stimuli. The parameters we measured in all three responses were unaffected by rsT 4 within the limit of variation between the six individual donors except for the slight mean 
effect at $30 \mu \mathrm{g} / \mathrm{ml}$ of $\mathrm{rsT} 4$, on the MLR proliferation. However, no inhibitory effect was observed when the experiments were extended to $200 \mu \mathrm{g} / \mathrm{ml}$ of rsT4. Under these experimental conditions, rsT4 remained intact physically with respect to the epitopes recognized by both OKT4 and OKT4a monoclonal antibodies, and it retained an active binding site for recombinant HIV-1 envelope glycoprotein, gp120. The lack of inhibitory effect by rsT4 in these systems could simply be attributed to the possibility that rsT4 is incapable of competing with membrane-bound CD4 for its physiological ligand even though it can bind to HIV gp160/120 and can be immunoprecipitated by both OKT4 and OKT4a antibodies (data not shown). Alternatively, it is possible that the CD4/MHC class II interaction only plays a prominent role under special conditions. Indeed, the enhancement of lymphocyte activation through CD4/MHC class II interaction was best demonstrated in a model system using cells with a lower level of $T$ cell receptors on the surface (17). A third possibility is that CD4 facilitates lymphocyte response by acting as a ligand for MHC class II molecules on antigen-presenting cells. If soluble CD4, like membrane-bound CD4, binds to class II molecules, rsT4 would participate in, rather than inhibit, the immune response.

While the physiological role of CD4 remains to be defined, the observation that rsT4 does not significantly inhibit the immune responses of peripheral blood lymphocytes induced by several different stimuli provides encouragement for its use in the therapy of AIDS, especially if the syndromes of primary HIV infection can be recognized, as recently described (30). These findings also raise interesting questions about the interactions between $\mathrm{CD}^{+} \mathrm{T}$ lymphocytes and MHC class II bearing antigen-presenting cells.

\section{Acknowledgments}

We would like to acknowledge B. Burrus and M. Crimmins for excellent technical assistance, D. MacDonald for manuscript preparation, and V. Sato and H. Eisen for scientific discussions and critical reading of the manuscript.

This work was supported in part by Physician Scientist Award AI-00679 to Dr. M. Liu from the National Institute of Allergy and Infectious Diseases of the National Institutes of Health and by Biogen Research Corporation.

\section{References}

1. Dalgleish, A. G., P. C. L. Beverley, P. R. Clapham, D. H. Crawford, M. F. Greaves, and R. A. Weiss. 1984. The CD4 (T4) antigen is an essential component of the receptor for the AIDS retrovirus. Nature (Lond.). 312:763-766.

2. Klatzmann, D., E. Champagne, S. Chamaret, J. Gruest, D. Guetard, T. Hercend, J.-C. Gluckman, and L. Montagnier. 1984. Tlymphocyte $\mathrm{T} 4$ molecule behaves as the receptor for human retrovirus LAV. Nature (Lond.). 312:767-768.

3. Maddon, P. J., A. G. Dalgleish, J. S. McDougal, P. R. Clapham, R. A. Weiss, and R. Axel. 1986. The T4 gene encodes the AIDS virus receptor and is expressed in the immune system and the brain. Cell. 47:333-348.

4. McDougal, J. S., M. S. Kennedy, J. M. Sligh, S. P. Cort, A. Mawle, and J. K. A. Nicholason. 1986. Binding of HTLV-III/LAV to $\mathrm{T}^{+} \mathrm{T}$ cells by a complex of the $110 \mathrm{~K}$ viral protein and the $\mathrm{T} 4$ molecule. Science (Wash. DC). 231:382-385.
5. Klatzmann, D., F. Barre-Sinoussi, M. T. Nugeyre, C. Douguet, E. Vilmer, C. Griscelli, F. Brun-Vezinet, C. Rouzioux, J. C. Gluckman, J.-C. Chermann, and L. Montagnier. 1984. Selective tropism of lymphadenopathy associated virus (LAV) for helper-inducer lymphocytes. Science (Wash. DC). 225:59-63.

6. Engleman, E. G., C. J. Geinke, F. C. Grumet, and R. L. Evans. 1981. Activation of human T lymphocyte subsets: helper and suppressor/cytotoxic T cells recognize and respond to distinct histocompatibility antigens. J. Immunol. 127:2124-2129.

7. Swain, S. L. 1983. T cell subsets and the recognition of MHC class. Immunol. Rev. 74:129-142.

8. Biddison, W. E., P. Rao, M. A. Talle, G. Goldstein, and S. Shaw. 1982. Possible involvement of the OKT4 molecule in T cell recognition of class II HLA antigens. J. Exp. Med. 156:1065-1076.

9. Krensky, A. M., C. S. Reiss, J. W. Mier, J. L. Strominger, and S. J. Burakoff. 1982. Long-term human cytolytic T-cell lines allospecific for HLA-DR6 antigen are OKT4 ${ }^{+}$. Proc. Natl. Acad. Sci. USA. 79:2365-2369.

10. Bensussan, A., S. C. Meuer, S. F. Schlossman, and E. L. Reinherz. 1984. Delineation of an immunoregulatory amplifier population recognizing autologous Ia molecules. J. Exp. Med. 159:559-576.

11. Meuer, S. C., S. F. Schlossman, and E. L. Reinherz. 1982. Clonal analysis of human cytotoxic T lymphocytes: T4+ and T8+ effector $\mathrm{T}$ cells recognize products of different major histocompatibility complex regions. Proc. Natl. Acad. Sci. USA. 79:4395-4399.

12. Greenstein, J. L., J. Kappler, P. Marrack, and S. J. Burakoff. 1984. The role of L3T4 in recognition of Ia by a cytotoxic, H-2D alpha-specific T cell hybridoma. J. Exp. Med. 159:1213-1224.

13. Greenstein, J. L., B. Malissen, and S. J. Burakoff. 1985. Role of L3T4 in antigen-driven activation of a class I-specific T cell hybridoma. J. Exp. Med. 162:369-374.

14. Sayre, P. H., and E. L. Reinherz. 1985. Structural invariance of $\mathrm{T} 4$ molecules from $\mathrm{T}$ cell clones of different antigen and major histocompatibility complex specificities. Eur. J. Immunol. 15:291-295.

15. Sleckman, B. P., A. Peterson, W. K. Jones, J. A. Foran, J. L. Greenstein, B. Seed, and S. J. Burakoff. 1987. Expression and function of CD4 in a murine T-cell hybridoma. Nature (Lond.). 328:351-353.

16. Doyle, C., and J. L. Strominger. 1987. Interaction between CD4 and class II MHC molecules mediates cell adhesion. Nature (Lond.). 330:256-259.

17. Gay, D., P. Maddon, R. Sekaly, M. A. Talle, M. Godfrey, E. Long, G. Goldstein, L. Chess, R. Axel, J. Kappler, and P. Marrack. 1987. Functional interaction between human T-cell protein CD4 and the major histocompatibility complex HLA-DR antigen. Nature (Lond.). 328:626-629.

18. Fisher, R. A., J. M. Bertonis, W. Meier, V. A. Johnson, D. S. Costopoulos, T. Liu, R. Tizard, B. D. Walker, M. S. Hirsch, R. T. Schooley, and R. A. Flavell. 1988. HIV infection is blocked in vitro by recombinant soluble CD4. Nature (Lond.). 331:76-78.

19. Hussey, R. E., N. E. Richardson, M. Kowalski, N. R. Brown, H.-C. Chang, R. F. Siliciano, T. Dorfman, B. Walker, J. Sodroski, and E. L. Reinherz. 1988. A soluble CD4 protein selectively inhibits HIV replication and syncytium formation. Nature (Lond.). 331:78-81.

20. Deen, K. C., J. S. McDougal, R. Inacker, G. Folena-Wasserman, J. Arthos, J. Rosenberg, P. J. Maddon, R. Axel, and R. W. Sweet. 1988. A soluble form of CD4 (T4) protein inhibits AIDS virus infection. Nature (Lond.). 331:82-84.

21. Traunecker, A., W. Luke, and K. Karjahinen. 1988. Soluble CD4 molecules neutralize human immunodeficiency virus type I. $\mathrm{Na}$ ture (Lond.). 331:84-86.

22. Smith, D. H., R. A. Byrn, S. A. Marsters, T. Gregory, J. E. Groopman, and D. J. Capon. 1987. Blocking of HIV-1 infectivity by a soluble, secreted form of the CD4 antigen. Science (Wash. DC). 238:1704-1707.

23. Strassman, G., and F. H. Bach. 1984. OKT4+ cytotoxic T cells can lyse targets via class I molecules and can be blocked by monoclonal antibody against T4 molecules. J. Immunol. 133:1705-1709. 
24. Rogozinski, L., A. Bass, and E. Glickman. 1984. The T4 surface antigen is involved in the induction of helper function. J. Immunol. 132:735-739.

25. Bank, I., and L. Chess. 1985. Purturbation of the T4 molecule transmits a negative signal to T cells. J. Exp. Med. 162:1294-1303.

26. Srendi, B., D. Volkman, R. H. Schwartz, and A. S. Fauci. 1981. Antigen-specific human T-cell clones: development of clones requiring HLA-DR-compatible presenting cells for stimulation in presence of antigen. Proc. Natl. Acad. Sci. USA. 78:1858-1862.

27. Meuer, S. C., D. A. Cooper, J. C. Hodgdon, R. E. Hussey, K. A. Fitzgerald, S. F. Schlossman, and E. L. Reinherz. 1983. Identification of the receptor for antigen and major histocompatibility complex on human inducer T lymphocytes. Science (Wash. DC). 222:1239-1242.
28. Reinherz, E. L., C. Morimoto, A. C. Penta, and S. F. Schlossman. 1980. Subpopulations of the T4+ inducer $T$ cell subset in man: evidence for an amplifier population preferentially expressing Ia antigen upon activation. J. Immunol. 126:67-70.

29. Carrera, A. C., F. Sanchez-Madrid, M. Lopez-Botet, C. Bernabeu, and M. O. DeLandazuri. 1987. Involvement of the CD4 molecule in a post-activation event on T cell proliferation. Eur. J. Immunol. 17:179-186

30. Tindall, B., S. Barker, B. Donovan, T. Barnes, J. Roberts, C. Kronenberg, J. Gold, R. Penny, D. Cooper, and the Sydney AIDS Study Group. 1988. Characterization of the acute clinical illness associated with human immunodeficiency virus infection. Arch. Intern. Med. 148:945-949. 